\author{
ARTIGO \\ do/ https://doi.org/10.22481/rpe.v16i43.6326
}

\title{
JUVENTUDE E FORMAÇÃO PROFISSIONAL DO CAMPO: RUPTURAS, CONTRADIÇÕES E CULTURA POLÍTICA
}

\author{
YOUTH AND VOCATIONAL TRAINING: RUPTURES, CONTRADICTIONS AND \\ POLITICAL CULTURE
}

\begin{abstract}
FORMACIÓN JUVENIL Y PROFESIONAL: RUPTURAS, CONTRADICCIONES Y CULTURA POLÍTICA
\end{abstract}

\author{
Ludmila Oliveira Holanda Cavalcante \\ Universidade Estadual de Feira de Santana - Brasil
}

Fabio Dantas de Souza Silva

Universidade Estadual de Feira de Santana - Brasil

Luciane Ferreira de Abreu

Instituto Federal de Educação, Ciência e Tecnologia Baiano - Brasil

\begin{abstract}
Resumo: O texto discute dimensões da pesquisa realizada entre 2016-2018 com financiamento do CNPq sobre juventude e formação para o trabalho no campo a partir da análise do perfil de jovens estudantes do Ensino Médio Subsequente frente aos desafios conjunturais que se instalaram nos anos de acirramento da política educacional no Brasil entre 2016 e 2018, levando em conta a consequente instabilidade dessas políticas para assistência e permanência da juventude nas instituições públicas da Rede Federal de Educação Profissional e Tecnológica que resultou em grande parte em um cenário de evasão escolar evidenciada ao longo do processo da pesquisa. Na metodologia da pesquisa, foram utilizados questionários individuais para levantamento do perfil socioeducacional dos sujeitos, etapa seguida pela realização de grupo focal para discussão das categorias: juventude, trabalho e campo. No que concerne ao fenômeno da evasão discente, os resultados apontaram que os sujeitos da pesquisa o compreendem a partir de uma visão meritocrática do cenário, atribuindo-o exclusivamente às condições individuais do estudante, o que pode sinalizar como os sujeitos percebem seus processos de formação distanciados da concepção de políticas educacionais como direito e do cenário de instabilidade socioeconômica que avançava nas condições familiares.
\end{abstract}

Palavras chave: Trabalho. Formação. Juventude rural

Abstract: The text discusses dimensions of the research carried out between 2016-2018 with funding from $\mathrm{CNPq}$ on youth and training for work in the field, based on the analysis of the profile of young students of the Subsequent High School in view of the conjuncture challenges that were installed in the years of political hardening education in Brazil between 2016 and 2018, taking into account the consequent instability of these policies for assistance and permanence of youth in public institutions of the Federal Network of Professional and Technological Education, which resulted in a large part in a 
scenario of school dropout evidenced throughout the process of education. In the research methodology, individual questionnaires were used to survey the socio-educational profile of the subjects, a step followed by a focus group to discuss the categories: youth, work and field. Regarding the phenomenon of student dropout, the results showed that the research subjects understand it from a meritocratic view of the scenario, attributing it exclusively to the individual conditions of the student, which can signal how the subjects perceive their training processes distanced from the conception of educational policies as a right and from the socioeconomic instability scenario that was advancing in family conditions.

Keywords: Job. Formation. Rural youth

Resumen: El texto discute dimensiones de la investigación realizada entre 2016-2018 con financiamiento del CNPq sobre juventud y formación para el trabajo en el campo, a partir del análisis del perfil de los jóvenes estudiantes del Bachillerato Posterior ante los desafíos coyunturales que se instalaron en los años de endurecimiento político educación en Brasil entre 2016 y 2018, tomando en cuenta la consecuente inestabilidad de estas políticas de atención y permanencia de los jóvenes en instituciones públicas de la Red Federal de Educación Profesional y Tecnológica, lo que resultó en gran parte en un escenario de deserción escolar evidenciado a lo largo del proceso educativo. En la metodología de la investigación se utilizaron cuestionarios individuales para relevar el perfil socioeducativo de los sujetos, paso seguido de un grupo focal para discutir las categorías: juventud, trabajo y campo. En cuanto al fenómeno de la deserción escolar, los resultados mostraron que los sujetos de investigación lo entienden desde una mirada meritocrática del escenario, atribuyéndolo exclusivamente a las condiciones individuales del estudiante, lo que puede señalar cómo los sujetos perciben sus procesos de formación. distanciados de la concepción de las políticas educativas como un derecho y del escenario de inestabilidad socioeconómica que avanzaba en las condiciones familiares.

Palabras clave: Trabajo. Formación. Juventud rural

\section{Introdução}

A conjuntura social, política e econômica atual no país tem sido demarcada por desafios limitadores para a juventude brasileira. Frente aos processos de recrudescimento da ofensiva neoliberal contra os trabalhadores e contra a população empobrecida, os jovens têm sentido acentuadamente os efeitos desses ataques, pois além das múltiplas inquietações peculiares sobre a construção de suas identidades nessa etapa do desenvolvimento humano, precisam lidar com situações adversas em busca de formação e trabalho.

Em 2016, com a saída de Dilma Rousseff do Governo Federal e a ascensão ao poder pelo seu então vice-presidente, Michel Temer, o desmonte das políticas sociais e direitos conquistados ao longo do período dos governos anteriores, foi se concretizando de forma acelerada dando vazão à uma sociedade elitista ressentida, desvencilhada das condições de vida da classe trabalhadora "a quem se negou sistematicamente o conhecimento escolar básico" (MOTA; FRIGOTTO, 2017, p.365). 
No Brasil do Michel Temer, um cenário de pauperização e crueldade vai se modelando sem disfarces no campo e nas cidades. Registros da Comissão Pastoral da Terra (CPT) via seu Relatório Anual intitulado "Conflitos no Campo - Brasil”, publicado anualmente deste 1985 com dados documentais sobre os índices de violência no campo, apontam para um incremento nos últimos anos de assustadora proporção. Segundo o Relatório, com dados do ano de 2017, "mais de $60 \%$ dos conflitos pela água foram protagonizados por mineradoras. 33 conflitos, $17 \%$, aconteceram no contexto das hidrelétricas. Outros 26 conflitos, 13\%, em áreas dominadas por fazendeiros." Importante salientar que segundo esta mesma fonte, o índice de violência de 2016-2017 (no período que sucede ao impeachment da Presidente Dilma Rousseff) vai chegar a 60,4\%, contra a média de 33\% do período anterior, entre 2011-2014.

Ainda em 2016 no MEC, inicia-se o processo de empobrecimento das pautas da Secretaria de Educação Continuada, Alfabetização, Diversidade e Inclusão (SECADI), fazendo parte do amplo projeto de desestruturação das políticas educacionais visceralmente construídas nas últimas décadas e que serão desidratadas e desnutridas no pari passu da inserção e "retorno" das forças conservadoras no Brasil.

Soma-se a este período pós impeachment, um franco processo de ruptura com as demandas de responsabilidade social junto às populações economicamente vulneráveis do Brasil, tendo como uma das suas marcas a aprovação em 2016, do Projeto de Emenda Constitucional (PEC 241) que teve como objetivo, congelar os gastos públicos com saúde e educação, pelos próximos 20 anos, apesar de toda a reação da população contrária ao pleito ${ }^{1}$. Ademais, foram aprovadas as reformas trabalhistas ${ }^{2}$, iniciando-se também o processo de implantação da reforma previdenciária ${ }^{3}$, está aprovada em 2019 no governo Bolsonaro, sendo parte do projeto de diminuição do Estado e ataque aos direitos sociais da classe trabalhadora.

Para agravar o cenário, os índices de desemprego no país indicam que o grupo social de jovens tem sido um dos mais afetados nos últimos anos, sendo que a parcela jovem ocupada geralmente atua nos trabalhos em condições precarizadas, recebem menor remuneração e poucas garantias de direitos trabalhistas em jornadas flexibilizadas.

No lastro desta conjuntura sócio-política na qual a juventude rural brasileira está inserida, discutimos neste texto dimensões da pesquisa financiada pelo $\mathrm{CNPq}$, realizada com jovens estudantes do curso Técnico em Agropecuária do Instituto Federal de Educação, Ciência e Tecnologia Baiano (IF Baiano), campus Catu, no período entre 2016 e 2018, que teve como

\footnotetext{
${ }^{1}$ Transformada na Emenda Constitucional 95/2016. DOU 16/12/16 PÁG 02 COL 02.

${ }^{2}$ Lei $\mathrm{N}^{\circ} 13.467$ de 13 de julho de 2017.

${ }^{3}$ Transformada na Emenda Constitucional 103/2019. DOU 13/11/19 PAG 01 SEC 01.
} 
objetivo "investigar a concepção de campo nas suas dimensões: educação, campo e trabalho para jovens estudantes do curso Técnico em Agropecuária na modalidade Subsequente". O curso Técnico em Agropecuária tem o perfil de formação de jovens para o trabalho no campo, que possui o objetivo de formar profissionais técnicos e alinhados com as tendências regionais e em conformidade com as demandas dos setores produtivos e os avanços tecnológicos (IF BAIANO, 2019).

Como produto da pesquisa realizada fizemos um registro fílmico intitulado Caminhos do Trabalho $(2018)^{4}$ com o objetivo de apresentar as narrativas que circundavam a experiência de estudantes junto ao curso Ensino Médio Subsequente com formação em Técnico em Agropecuária e a partir disto, socializar este material didático para processos educativos, capaz de elucidar a forma como estes jovens percebem a trajetória formativa do curso técnico, rumo ao trabalho de especificidades rurais.

O debate sobre a categoria "juventude" tornou-se central no estudo, uma vez que, os estudantes que frequentam o Curso estão na faixa etária dos 15-29 anos. Cientes das limitações ao conceito de juventude a partir de uma demarcação cronológica, a pesquisa centrou esforços em assegurar um olhar sobre a perspectiva de juventude rural e, desse modo, foi utilizado o debate de Castro (2009, p.182) para definir que juventude é, "além de uma categoria que representa identidades sociais, uma forma de classificação social que pode ter múltiplos significados, mas que vem se desenhando em diferentes contextos como uma categoria marcada por relações de hierarquia social.” Nessa perspectiva, essa definição desconstrói a concepção que trata juventude como categoria "auto-evidente ou auto explicativa, utilizando idade e/ou comportamento como definições metodológicas" (p.184).

Buscando superar de um lado a naturalização e homogeneização, ao se compreender os jovens somente a partir do recorte etário/geracional, e de outro a sua diluição em uma diversidade que os tornam invisíveis socialmente, Leão e Antunes-Rocha (2015) apoiados nos conceitos de Abramo (2005) e Dayrell (2007), propõem compreender os jovens a partir da ideia de "Condição Juvenil".

Esse termo reconhece que toda sociedade constrói representações sociais e atribui determinados valores à juventude a partir de um recorte geracional. Ao mesmo tempo, não desvincula isso das especificidades de cada situação social vivida a partir dos condicionantes de classe, gênero, pertencimento étnicoracial, etc. (LEÃO; ANTUNES-ROCHA, 2015, p. 19)

\footnotetext{
${ }^{4} \mathrm{O}$ documentário de 35 minutos teve como proposta tornar-se um material didático para processos educativos, capaz de elucidar a forma como as estudantes percebem a trajetória formativa do curso técnico, rumo ao trabalho de especificidades rurais.
} 
Assim, estudar os jovens é investigar as relações sociais em que eles estão inseridos, buscando compreender as dimensões simbólicas e culturais. Daí que, o debate sobre juventude rural é especifico, no sentido de compreender como essas pessoas vivem a experiência do meio rural como jovens.

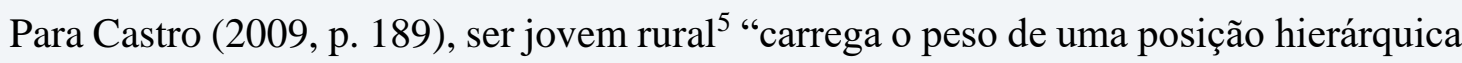
de submissão, em um contexto ainda marcado por difíceis condições econômicas e sociais para a produção familiar". É neste contexto que o jovem rural está inserido, um tempo histórico no qual as mazelas da sociedade capitalista se intensificaram no campo brasileiro.

Neste artigo, analisaremos o perfil dos/das jovens estudantes do Ensino Médio Subsequente frente aos desafios conjunturais que se instalaram nos anos de acirramento da política educacional no Brasil entre 2016 e 2018, levando em conta a consequente instabilidade dessas políticas para assistência e permanência da juventude nas instituições públicas da Rede Federal de Educação Profissional e Tecnológica que resultou em grande parte em um cenário de evasão escolar evidenciada ao longo do processo da pesquisa. Ressaltamos que há duas instituições da referida Rede Federal no estado da Bahia: o Instituto Federal de Educação, Ciência e Tecnologia da Bahia (IFBA) e o Instituto Federal de Educação, Ciência e Tecnologia Baiano (IF Baiano). Os sujeitos da pesquisa realizada são estudantes de uma das unidades do IF Baiano, o campus Catu.

\section{Metodologia}

Pautada em uma perspectiva crítica, a pesquisa de cunho qualitativo, teve como categorias teóricas a discussão de juventude rural, campo e trabalho com o objetivo de compreender a relação juventude e formação para o trabalho no campo a partir da concepção dos jovens. Como referência analítica, o estudo voltou-se para os debates da Educação do Campo que busca situar as condições de vida dos sujeitos do campo sob uma perspectiva de projeto de sociedade contra hegemônico, na disputa pelas relações de poder dentro da sociedade capitalista. O "campo" aqui visto como um território de disputa política, que demanda a formação de sujeitos coletivos em busca de autonomia de produção, terra, trabalho e condições de vida dignas na zona rural. Assim como debruçou-se sobre a categoria "juventude"

\footnotetext{
5 Embora nossa categoria analítica seja a opção pelos termos educação do campo e campo, na pesquisa, utilizamos "rural" cientes da nomenclatura adotada pelos estudantes. A perspectiva "campo" compreendida nos estudos da educação do campo (FERNANDES, 2005; ARROYO; CALDART; MOLINA, 2004) não encontrava ressonância nos discursos dos jovens desde os questionários e encontros do grupo focal, sendo assim não foi adotada nas terminologias das entrevistas.
} 
Inicialmente, o projeto previa a realização da coleta de dados com os jovens matriculados na turma de 2015-2016, entretanto, ao observar-se que concluiriam o curso no primeiro semestre de 2016, quando iniciada a pesquisa, optou-se por convidar os estudantes da turma 2016-2017 (Turma A) pois assim haveria mais disponibilidade de tempo com esses sujeitos para desenvolvimento das etapas previstas. Nessa turma, 20 alunos responderam ao questionário, ocorreu que entre o processo de aplicação dos questionários e a realização das etapas com o grupo focal foi possível observar um número significativo de evasão dos jovens matriculados no curso e a equipe sentiu a necessidade de ampliar o quantitativo dos sujeitos de pesquisa, assegurando uma maior representatividade dos estudantes, incluindo a turma 20172018 (Turma B) do curso Técnico em Agropecuária na modalidade Subsequente, totalizando duas turmas com um universo de 40 estudantes participantes da pesquisa ao longo dos anos 2016-2018. Este universo de 40 estudantes foi tomado como base para traçar um perfil do grupo que representa os estudantes do Ensino Médio subsequente na referida instituição.

O estudo foi realizado com um total de 40 estudantes do Curso Técnico em Agropecuária, oriundos das turmas de 2016 e 2017. Os instrumentos de coletas de dados foram questionários, grupo focal, entrevistas e visitas a campo. Foram aplicados 40 questionários com questões abertas e fechadas, que visaram obter dados dos perfis sócio educacionais destes jovens que adentram o Curso Técnico em Agropecuária no campus Catu. Foram realizados encontros de grupos focais (GONDIM, 2003) ${ }^{6}$.

Os grupos focais podem servir a diversos propósitos. Conforme Fern (2001 apud GONDIM 2003) há duas orientações: a primeira visa a confirmação de hipóteses e a avaliação da teoria, mais comumente adotada por acadêmicos. A segunda, por sua vez, dirige-se para as aplicações práticas, ou seja, o uso dos achados em contextos particulares. Estas duas orientações podem estar combinadas em três modalidades de grupos focais: exploratórios, clínicos e vivenciais.

Morgan (1997) adotou uma perspectiva distinta para classificar os grupos focais. De acordo com ele há também três modalidades, mas sua tipologia repousa no uso isolado ou concomitante de outras técnicas e métodos de pesquisa. Desse modo, o autor fala em: a) grupos autorreferentes, usados como principal fonte de dados; b) grupos focais como técnica complementar, em que o grupo serve de estudo preliminar na avaliação de programas de

\footnotetext{
${ }^{6}$ Para o autor, o grupo focal ocupa uma posição intermediária entre a observação participante e as entrevistas em profundidade. Desse modo, o grupo focal se diferencia de uma entrevista individual por basear-se na interação entre as pessoas para obter os dados necessários, isto é, a interação entre os sujeitos pesquisados sobre a temática discutida será de extrema importância para a análise do pesquisador.
} 
intervenção e construção de questionários e escalas; c) grupo focal como uma proposta multimétodos qualitativos, que integra seus resultados com os da observação participante e da entrevista em profundidade. (GONDIM, 2003). Nesta pesquisa, o grupo focal, foi utilizado como mais uma ferramenta no processo de coleta e análise de dados com o propósito metodológico de compreender como os/as jovens percebem os temas da juventude e trabalho Como forma de organizar os dados nos grupos focais, chamamos de Etapa 1 a realização do trabalho com a turma 2016-2017 e Etapa 2 com a turma de 2017-2018. O trabalho no grupo focal teve como objetivo a interação dos jovens com as categorias Juventude, Campo e Trabalho, no sentido de observar como esses jovens compreendem as discussões em torno dessas categorias e como avaliam as suas vidas frente a estes temas. Desse modo, primeiro foi realizado a coleta de dados com questionários e grupo focal com a Turma $\mathrm{A}$ e depois o procedimento junto à turma $\mathrm{B}$. Para efeito das entrevistas, etapa posterior ao processo inicial, selecionamos os jovens que se interessaram pelo trabalho com a pesquisa e que poderiam nos responder às questões levantadas ao longo do nosso trabalho com as turmas. Todas as etapas da pesquisa de campo foram devidamente autorizadas pelos participantes da pesquisa que assinaram os termos de Consentimentos Livres e Esclarecidos (TCLE), e asseguraram os direitos de imagem para fins de publicação do trabalho realizado.

\section{Perfil estudantil dos estudantes e desafios do processo de formação no ensino médio subsequente}

Como dito anteriormente, dentre as dificuldades encontradas para realização da pesquisa, no primeiro momento a equipe pesquisadora deparou-se com a evasão de estudantes nas turmas delineadas inicialmente para aplicação dos questionários. De acordo com Moraes (MORAES et al, 2018), a taxa de evasão afere o percentual de matrículas que perderam o vínculo com a instituição no ano de 2017 sem a conclusão do curso em relação ao total de matriculas. Os indicadores institucionais sobre evasão discente ratificaram nossas percepções sobre esse fenômeno pois, no ano de 2017 a taxa de evasão nos cursos presenciais ofertados na forma subsequente foi de $36,8 \%$. A situação se agrava ao considerarmos, especificamente, os dados relativos aos cursos presenciais subsequentes em Agropecuária em um Instituto Federal, pois a taxa de evasão aumenta para 39,8\% (BRASIL, 2018).

Os dados encontrados na pesquisa sobre evasão reforçam as dificuldades da juventude da classe trabalhadora de permanecer nos cursos de formação. Esta constatação está diretamente 
relacionada com o crescimento de jovens que não estudam, não trabalham e não se qualificam profissionalmente.

Segundo os dados da PNAD de 2017, o número de pessoas entre 15 e 29 anos que não trabalham, não estudam e não se qualificam profissionalmente, cresceu 5,9\% de 2016 para 2017, o que equivale a mais de 619 mil pessoas. Em 2016 eram 10,5 milhões, número que cresceu para 11,2 milhões em 2017, de um contingente de 48,5 milhões de pessoas nessa faixa etária. (KUENZER, 2020, p. 59)

No que concerne o perfil do grupo analisado, dados da pesquisa (2016-2018) apontaram que metade dos jovens entrevistados afirmou ter apoio de Programas Sociais nas suas famílias. Entre os Programas Sociais, 97,5\% estavam com o Bolsa Família e 12,5\% com o Programa "Minha casa, minha vida". $80 \%$ dos jovens afirmam receber auxílio financeiro da instituição de ensino, via política de permanência como, por exemplo, auxílio-transporte, material acadêmico, moradia.

Os estudantes na sua maioria são originários da escola pública (85\% cursaram o Ensino fundamental I, 90\% cursaram o Ensino Fundamental II e 97,5\% cursaram o Ensino Médio em escolas públicas). Mesmo com a presença da escola fundamental na zona rural, apenas 17,5\% deles estudaram na zona rural, $75 \%$ dos estudantes afirmam ter estudado na zona urbana dos seus municípios e 7,5\% não responderam a esta questão. Para o Ensino Fundamental II (da $5^{\mathrm{a}}$ à $8^{\mathrm{a}}$ série), $80 \%$ disseram ter cursado em escolas urbanas e apenas $10 \%$ em escolas rurais. Para o Ensino Médio, 87,5\% dos estudantes afirmam ter estudado em escolas públicas da zona urbana.

Do total de estudantes, 30\% concluíram o Ensino Médio entre os anos de 2016 e 2017. A grande maioria (50\%) afirmou ter concluído essa etapa entre os anos de 2010 e 2015 . Apenas $5 \%$ dos jovens afirmam ter evadido da escola durante o seu percurso estudantil, dentre os motivos foram anunciados "casamento" e "dificuldade de adaptação ao ensino à distância".

Podemos afirmar que estes jovens que concluíram o Ensino Médio no Brasil fazem parte de um grupo minoritário no país, pois dados da OCDE informam que mais da metade dos adultos (52\%) com idade de 25 a 64 anos não atingiram essa etapa de formação. Para Kuenzer (2020, p. 59), no estudo sobre Ensino Médio, informa que é nesta etapa da educação básica "que estão as taxas mais altas de atraso e evasão, indicando que os jovens se distanciam das possibilidades de acesso à educação, enquanto direito fundamental”.

Após o término do Ensino Médio e em busca da formação profissional, rompendo de certo modo, com as estatísticas que revelam a negação do direito à educação, buscamos 
compreender o que levou os estudantes pesquisados a escolherem o referido curso. Desse modo, $75 \%$ dos estudantes afirmaram que escolheram o Curso de Agropecuária por "gostar da área". $15 \%$ falaram da indicação da família para realização do curso, há os que justificaram ser o curso um meio de "melhorar a condição de vida da família" ou "obter experiência com horticultura" e interesse em "se especializar em gado leiteiro" (10\%), e os que afirmaram ter sido por falta de opção de outros cursos técnicos (2,5\%). Para $85 \%$ dos estudantes, este é o primeiro curso técnico de suas vidas.

A pesquisa buscou verificar se entre os jovens havia algum indicador de participação em cenários de organização social e coletiva, ponto de extrema relevância para os estudos da "educação do campo", mas as respostas aos questionários revelaram não haver entre estes jovens uma cultura de participação social em coletivos organizacionais. Ao serem questionados se participavam de contextos como associação, cooperativa, movimentos sociais, sindicatos, grupo de jovens, grupo de igreja... 90\% dos jovens afirmaram não ter envolvimento com essas organizações, $10 \%$ dos jovens responderam que estavam envolvidos em grupos da igreja e associações comunitárias. Ou seja, são cenários de vida que pouco estão conectados com os pressupostos da educação do campo, que demanda o envolvimento dos jovens nos coletivos de luta pela terra e condições de vida no rural.

No que concerne a produção e a posse de terras na zona rural, segundo os questionários analisados, 42,5\% das famílias dos jovens são proprietárias de áreas rurais com extensão média de 2,9 hectares, exceto a família de um jovem que possui propriedade maior de 260 hectares. Nessas áreas rurais são cultivados: "mandioca, frutíferas, capim e são criados bovinos, caprinos e equinos".

Segundo dados da pesquisa, os/as estudantes do IF baiano, entraram na instituição em busca de melhor qualificação profissional e com objetivos claros de incrementar a vida profissional, seja na área da agropecuária ou nas áreas afins. No decorrer da pesquisa, foi possível verificar que o perfil dos estudantes do curso do ensino médio subsequente no interior da Bahia, segue um padrão de jovem de classe baixa e média baixa, interessado em processos formativos consistentes, capazes de proporcionar um horizonte de futuro diferente da trajetória de suas famílias no campo. A instituição é percebida como um lugar de estudo privilegiado e uma forma certeira de dar vazão aos planos de carreira e ambição de "ser alguém na vida".

Dados da pesquisa, no entanto, demonstram que esse projeto de vida nem sempre se concretiza de forma satisfatória. 


\section{Fazer parte do Instituto Federal: desafios entre o ingresso e a permanência estudantil}

Em linhas gerais, o movimento feito pelos estudantes para qualificar-se após a conclusão do ensino médio, ilustra o quadro de demandas por essa modalidade de educação profissional no país no ano de 2017. Segundo dados do Instituto Brasileiro de Geografia e Estatística (IBGE), dentre as 56,6 milhões de pessoas aptas ${ }^{7}$ a frequentarem um curso técnico de nível médio, 3,5\% delas frequentavam algum curso técnico de nível médio, ou cerca de 2 milhões de indivíduos. Desse total de matriculados nos cursos técnicos de nível médio, 57,8\% eram alunos de cursos técnicos da modalidade subsequente (IBGE, 2018b).

No âmbito da Rede Federal de Educação Profissional e Tecnológica, a evasão estudantil tem sido objeto de análise do Ministério da Educação (MEC) e da Secretaria de Educação Profissional e Tecnológica (SETEC) que elaboraram orientações para a superação da evasão e retenção discente a partir de um trabalho coletivo com as instituições da Rede Federal com foco na qualidade do ensino, no atendimento à diversidade e na permanência e êxito dos estudantes no processo educativo. O trabalho de construção dessas orientações envolveu atividades de pesquisas exploratórias e diagnósticas com o objetivo de definir a base conceitual da análise, dimensionar os fenômenos da evasão e retenção, discutir e analisar os dados de matrícula, retenção e conclusão dos cursos e categorizar e definir causas da evasão e retenção e medidas para superação, com base na literatura e em diagnósticos locais realizados pelas instituições que integram a Rede Federal (BRASIL, 2014).

$\mathrm{Na}$ análise dos referidos diagnósticos locais realizados pelas instituições da Rede Federal as causas da evasão e da retenção discente foram categorizadas por fatores: fatores individuais, fatores internos às instituições e fatores externos às instituições. Dentre os fatores individuais constam aspectos relacionados às características do estudante como capacidade de aprendizagem e habilidades de estudo, conciliação entre estudos e exigências do mundo do trabalho, envolvimento com o curso escolhido, qualidade da formação escolar anterior, questões de ordem pessoal ou familiar, questões financeiras do estudante, dentre outros. Os fatores internos às instituições referem-se à infraestrutura, ao currículo, a gestão administrativa e didático-pedagógica da instituição como valorização e formação de professores, eficiência de programas de assistência estudantil, gestão financeira da instituição, respeito à diversidade e inclusão social. E na categoria de fatores externos há os aspectos relacionados às dificuldades

7 Pessoas aptas, nesse contexto, refere-se ao conjunto de estudantes do ensino médio regular ou Educação de Jovens e Adultos ou aqueles que concluíram essa etapa da formação sem ter alcançado o ensino superior completo (IBGE, 2018). 
financeiras do estudante para permanência no curso e exercício da profissão pretendida como a conjuntura socioeconômica, possibilidades de trabalho e desenvolvimento tecnológico da área de atuação (BRASIL, 2014).

Considerando as causas da evasão e retenção discente apontadas nos diagnósticos que possibilitaram aprofundar a compreensão do problema, as unidades da Rede Federal foram conduzidas a desenvolverem um Plano Estratégico de Intervenção e Monitoramento para Superação da Evasão e Retenção, sob a justificativa da necessária articulação e implementação de políticas institucionais efetivas para o atendimento dos estudantes, cujo perfil é majoritariamente de egressos de escolas públicas e integrantes de famílias em vulnerabilidade socioeconômica (BRASIL, 2014).

A partir dessas orientações, o IF Baiano elaborou o Plano Estratégico Institucional para a Permanência e Êxito dos Estudantes, anunciando como objetivo primordial "o enfrentamento, acompanhamento e combate à evasão e retenção, por meio de ações administrativas e pedagógicas que deverão ser estabelecidas e desenvolvidas em conjunto com toda comunidade acadêmica" (IF BAIANO, 2016, p. 16). O documento apresenta a caracterização da instituição, os diagnósticos quantitativos e qualitativo sobre os indicadores de evasão e retenção, a estratégia de intervenção, de monitoramento dos indicadores e das ações de intervenção e de avaliação do plano.

Do ponto de vista institucional, dentre as estratégias de intervenção para superação da retenção e evasão nos cursos subsequentes previstas para implementação no ano de 2017 destacam-se os programas de Assistência Estudantil com metas de ampliação do número de bolsas auxílio, da residência e alimentação estudantil e incentivo à participação dos estudantes em atividades de pesquisa e extensão, além dos programas de Tutoria e Monitoria que visam melhorias nos processos de aprendizagem (IF BAIANO, 2016) ${ }^{8}$.

É válido salientar que no ano de 2016 havia um investimento de R \$ 4.642.894,29 para atender a essas políticas de permanência estudantil. Esse investimento, no entanto, vai sofrendo alterações ao longo dos últimos anos, bem como o número de matrículas. Em 2018, verificamos que esse investimento ficou no montante de $\mathrm{R} \$ 6.198 .347,00$, o que a primeira vista poderia ser percebido como incremento do recurso financeiro. No entanto, quando comparado ao número de matrículas percebemos que a proporcionalidade entre investimento e alunos matriculados foi mantida, mesmo com aumento de $32,2 \%$ no número de matriculados na instituição nesse

\footnotetext{
8 Tais ações, se tiverem sido implementadas em conjunto com outras estratégias de natureza administrativa e pedagógica, podem ter colaborado para a redução das taxas de evasão dos cursos subsequentes em 2019 que foi de 31,4\% enquanto que nos cursos de Agropecuária ficaram em 23,8\% (BRASIL, 2020).
} 
período, pois no que concerne à assistência estudantil o investimento anual por aluno no ano de 2016 foi de R \$ 376,73 e em 2018 o valor foi de R\$ 377,30 (IF BAIANO, 2016; 2018).

Ainda no que concerne aos desafios da permanência na Instituição, é válido situar o debate da representação estudantil no Campus estudado, no período 2016-2018, que como foi dito anteriormente foi marcado por disputas de ordem sócio-políticas e educacionais no cenário nacional. No que concerne ao cenário local, na instituição analisada havia dois tipos de organizações de representação estudantil: o Grêmio Estudantil Edson Luís Souto (GEELS) que representa os estudantes dos cursos de nível médio e os Diretórios Acadêmicos que representam os estudantes dos cursos de nível superior. Ambos vinculados ao Movimento Estudantil Unificado do IF Baiano (ME), organização que congrega as diversas representações estudantis dos campi.

Nessa conjuntura, o coletivo de estudantes posicionou-se de forma contundente e demonstrou compreender as perversas implicações das medidas de ajuste fiscal defendidas pelo Governo Temer. A reforma do Ensino Médio, a Proposta de Emenda Constitucional No 241 e 55 (PEC dos Gastos Públicos) que tramitava no Congresso, a reforma da Previdência Social, a reforma trabalhista e o projeto de lei Escola sem Partido foram propostas que o GEELS qualificou como arbitrárias, pois poderiam comprometer a destinação dos investimentos financeiros para os serviços públicos, poderiam ampliar a precarização das condições de trabalho dos trabalhadores e poderiam limitar a autonomia dos professores e estudantes no processo de construção do conhecimento.

Focado nessa pauta nacional o grêmio estudantil decidiu pela ocupação das dependências físicas do Campus Catu no dia 20 de outubro de 2016, como estratégia de resistência e fortalecimento dos movimentos estudantis de ocupação das escolas que tinham ganhado corpo pelo país, em protesto contra as medidas do Governo Temer. No primeiro momento, os servidores e visitantes foram impedidos de entrar nos prédios principais do campus onde ocorrem as atividades administrativas e pedagógicas e posteriormente houve a liberação da entrada de alguns servidores de setores administrativos, após negociação estabelecida entre o movimento estudantil e a Direção Geral do campus. A mobilização foi comunicada à Direção Geral do Campus e à Reitoria do IF Baiano através do ofício No 02/2016 que tratou do assunto "Ocupação estudantil em prol de um país digno" e das bandeiras de luta:

1. Ilegitimidade do governo Temer;

2. Contra a PEC 241 (congelamento de gastos);

3. Contra a Escola sem Partido; 
4. Contra a normativa de $\mathrm{N}^{\circ} 20$ no MEC (reduz a oferta de vagas pelas instituições de nível superior);

5. Contra MP 746 (reforma do Ensino médio);

6. Contra aumento da idade mínima obrigatória de aposentadoria para 65 anos;

7. Contra o aumento da carga horária para $80 \mathrm{~h}$ semanais de trabalho;

8. Cumprir e fazer cumprir no IF Baiano - Campus Catu o Estatuto do Grêmio Estudantil;

9. Atenção às demandas apresentadas no memorando $03,05,17$, assim como as demandas já apresentadas pelo curso Técnico em Agropecuária;

10. Liberação da piscina aos internos nos finais de semana;

11. Falta de estrutura e equipamentos para aulas práticas ou até mesmo aulas convencionais. (GEELS, 2016).

Mais tarde o coletivo estudantil GEELS participou da assembleia do Sindicato Nacional dos Servidores Federais da Educação Básica, Técnica e Tecnológica (SINASEFE), seção Catu, oportunidade em que reiterou a pauta do movimento estudantil para os presentes e obteve o apoio dos servidores. Ainda nessa assembleia os estudantes se prontificaram a aderir ao Dia Nacional em Defesa do Serviço Público nos dias 24 e 25 de outubro de 2016 e participar da caravana à Brasília organizada pelo SINASEFE local. Também fez parte da agenda de atividades do primeiro dia de ocupação do Campus a realização de debates temáticos sobre Questões Étnico-raciais, LGBT's, Mulheres e "Governo Temeroso", organizados e mediados pelos próprios estudantes.

Além da participação na referida caravana à Brasília com servidores do IF Baiano e 22 estudantes, houve atividades do movimento estudantil no município. A agenda contemplava a participação em programas locais de rádio para divulgar o movimento para a população, reuniões com a Direção Geral do Campus para negociação das reivindicações locais, protesto com os estudantes das escolas municipais e estaduais na principal rodovia de acesso ao município e participação nos Jogos Internos do IF local. Estes jogos estavam previstos no calendário acadêmico como atividade regular do Campus e não foi suspensa pelo movimento de ocupação como estratégia de resistência contra a reforma do Ensino Médio que desobrigava as instituições escolares da oferta da disciplina Educação Física nessa etapa de ensino. Assim, o movimento de ocupação e a Direção Geral do Campus articularam para a manutenção da atividade e divulgaram uma nota de esclarecimento à Comunidade Acadêmica, se posicionando frente a medida provisória do novo ensino médio na qual criticavam a "obrigatoriedade de disciplinas elementares no processo de educação/construção do cidadão enquanto agentes transformadores, tais como Filosofia, Sociologia, Arte e Educação Física” (COMISSÃO ORGANIZADORA JOIF, 2016). 
Compreendendo o caráter pedagógico da resistência para a formação política de servidores e estudantes, o movimento de ocupação do campus, em articulação de estratégias de luta junto ao SINASEFE, realizou mais ciclos de debates para aprofundamento dos temas que cotidianamente são abordados nas tarefas dos movimentos.

O ciclo de debates foi iniciado com o tema da Reforma Política: perspectiva histórica, legislação vigente e propostas em tramitação. Posteriormente foram realizados debates sobre os temas da PEC 55 - a PEC da Morte, Consciência Negra: a opressão racial a partir das reformas do Governo Temer, Identidade de Gênero e Sexualidade e sobre a Reforma do Ensino Médio e o Projeto de Lei Escola sem Partido. Os estudantes se destacaram na realização dessas atividades, quer seja participando na organização e logística, na mediação dos debates, na participação na plenária e nas próprias mesas como debatedores ao lado dos especialistas convidados.

A Greve Geral do dia 11 de novembro de 2016, em resposta à convocação nacional das centrais dos trabalhadores contou com a participação efetiva do movimento estudantil. Foram realizadas reuniões com outras instituições representativas de trabalhadores como o Sindicato dos Trabalhadores em Educação do Estado da Bahia (APLB) e o Sindicato dos Petroleiros da Bahia (SINDIPETRO) para construção desse dia de luta, concretizado através de distribuição de panfletos informativos sobre as motivações do movimento durante o fechamento da principal rodovia de acesso ao município. Entretanto, a Greve Geral proposta para o dia 25 de novembro no município, não ocorreu por dificuldades de articulação com os sindicatos de trabalhadores de outras categorias externas.

A dificuldade de articulação e mobilização social é um ponto de discussão que nos interessa nesse texto no que concerne à participação dos estudantes do curso Técnico em Agropecuária ensino médio subsequente no período estudado.

\section{Educação Profissional, cultura política e estudantes do curso Técnico em Agropecuária subsequente}

Na pesquisa empírica a terminologia mais comumente adotada quando se referindo ao espaço de formação e trabalho nas narrativas dos jovens foi "rural", ainda que por vezes, o termo "campo" ressurgisse aqui e ali. Esta alternância da linguagem demonstrou uma suposta "equivalência" de sinônimo que não corresponde aos debates da educação do campo (BRASIL, 2002). 
O termo rural mostrou-se como um universo conceitual ambíguo, deslocado e desafiador para a proposta de compreensão do projeto da educação do campo e sua disputa contra hegemônica. Para Souza (2012):

As experiências e lutas da educação do campo colocam em evidência a histórica desigualdade educacional da sociedade brasileira, em que os trabalhadores são os que possuem menor escolaridade. Também, dão ênfase aos diversos problemas estruturais e conjunturais, tais como concentração da terra e dificuldades materiais para a efetivação da produção agrícola e geração de empregos nas pequenas propriedades e nos assentamentos de reforma agrária, entre tantas outras. (SOUZA, 2012, p.8).

Para a equipe de pesquisadores foi importante compreender, desde o início, que a terminologia "campo" como pensada e construída na dinâmica dos movimentos sociais e legislação educacional atual (BRASIL, 2002), não fazia parte das narrativas das estudantes e não tinha o mesmo sentido político pedagógico atribuído aos sujeitos do campo, como previsto em Arroyo, Caldart, Molina (2004), “campo é o rural em movimento”. Nesta experiência de pesquisa junto às jovens, os termos "rural" e "campo", são utilizados sem diferenciação, sem conflitos semânticos ou de natureza política. Como a pesquisa visava, inicialmente, apreender a percepção dos jovens, observamos que o termo "rural" situava os sujeitos na dinâmica que movimentava suas compreensões do lugar, seja como lugar de origem, seja como lugar de aconchego, seja como lugar de trabalho e referência em alguma circunstância de suas vidas. Dessa forma, "campo" e "rural" eram expressões usadas para se referirem aos territórios de mesmo significado na linguagem das estudantes entrevistadas. De posse da organização semântica no trabalho com a pesquisa, a palavra "campo" tornou-se muitas vezes "zona rural" esta que, no contexto dos coletivos estudantis e profissionais da instituição, transitava com naturalidade nas conversas entre os pares no percurso da pesquisa e que parecia traduzir a compreensão do espaço social daquelas pessoas.

Há uma relação de afinidade com o campo, este lugar de envolvimento com família e trajetória sociocultural de suas vidas. Essa implicação com as atividades relacionadas ao campo foi observada, também, nas falas das jovens que construíram suas histórias de vida na cidade, sempre observando como a formação profissional tem o campo como um lugar de conexão e vida.

As falas, no entanto, quando se reportam às cidades onde moram, trazem a perspectiva instigante de como compreendem o tema a partir das dimensões de cidade, a (grande), a cidade 
"do outro", ou pequena, a "minha cidade" que, mesmo sendo no espaço urbano, pouco tem a oferecer.

\begin{abstract}
Minha cidade onde eu moro não tem muitas oportunidade pros jovens porque é uma cidade pequena, a cidade não tem muito local de lazer, a cidade tem um rio mas é poluído, a cidade tem uma praça só que essa praça não é mais usada como lazer[...]E minha cidade não tem muita coisa não. Só tem mais bares, restaurantes... é uma cidade pequena. (Ana Kely - entrevista 2018).

Quando eu entrei lá (na instituição de ensino profissionalizante) muitos me falaram assim: você não vai conseguir nada porque aqui na cidade não tem oportunidades, você vai ter que sair pra fora do estado. [...], mas quando eu entrei lá que eu vi como é ampla essa área eu percebi que não preciso sair daqui pra mostrar o que eu aprendi e buscar melhores condições pra poder atuar na área que eu escolhi (Myra entrevista 2018).

Os jovens estão precisando de mais oportunidades. E a minha cidade [referindo-se a cidade onde mora] necessita de oportunidades para os jovens porque aqui a gente tem uma população de jovens muito grande eu acho que a implementação de mais universidades aqui seria uma boa. E aumentar a grade curricular daqui, do ensino superior também seria ótimo. (Jordane - Entrevista 2018).

Não tem muita oportunidade porque lá é uma cidade pequena assim. É um lugar que não tem muita opção de empregos e de estudo também. (Michele - Entrevista 2018).
\end{abstract}

Segundo Santos (2012):

O espaço é a matéria trabalhada por excelência. Nenhum dos objetos sociais tem uma tamanha imposição sobre o homem, nenhum está tão presente no cotidiano dos indivíduos. A casa, o lugar de trabalho, os pontos de encontro, os caminhos que unem esses pontos são igualmente elementos passivos que condicionam a atividade dos homens e comandam a prática social. A práxis, ingrediente fundamental da transformação da natureza humana, é um dado socioeconômico, mas é também tributária dos imperativos espaciais. (SANTOS, 2012, p. 34).

$\mathrm{Na}$ narrativa das jovens, cidade e o campo são espaços de diferentes sentidos e significados e elas transitam entre eles expressando contradições, desejos, memórias, planos e incertezas de futuro atreladas ao espaço que vivem.

Castro et al (2009), ao analisar processos de organização da juventude rural nos movimentos sociais percebe que há uma dinâmica de consolidação em torno da "construção de um novo ator político", a partir da verificação de maior visibilidade da juventude rural tanto no campo acadêmico como no campo político. Isto significa maior participação da juventude nos processos decisórios dos movimentos sociais e nas articulações com o poder público. Esse processo de construção foi conquistado aos poucos e está em curso, ainda que permeado por contradições, pois o distanciamento entre o discurso e a prática relacionados ao envolvimento 
efetivo dos jovens nesses coletivos é uma realidade demarcada por tensões de toda ordem como conflitos geracionais, hierarquia familiar, migração para as cidades e elementos identitários.

Em que pese o protagonismo assumido pelo Grêmio Estudantil nas mobilizações ocorridas em 2016 não foi possível identificar o grau de participação dos jovens sujeitos da pesquisa realizada no coletivo de mobilização estudantil institucional. Isto nos instiga a pensar sobre os espaços de atuação política não ocupados por esses jovens enquanto sujeitos em formação para o trabalho do campo. Mesmo compartilhando a instituição escolar com colegas que encamparam a luta coletiva pela educação, os jovens sujeitos pareciam mais focados na "aprendizagem das técnicas da área ensinada no curso" e na conclusão do período letivo para se formarem como técnicos em agropecuária com condições de disputar vagas no mundo do trabalho. Desejo legítimo de inserção profissional e de melhoria das suas realidades objetivas de sobrevivência num país que tem oferecido oportunidades de formação e trabalho insuficientes para a juventude. Por outro lado, em contraposição ao debate da Educação do Campo e em acordo com a análise de Castro et al (2009), isto demonstra os obstáculos que a juventude rural encontra para se organizar como coletivo, pois ser jovem rural pressupõe lidar com múltiplas desigualdades e violências, o que pode levá-lo a priorizar seus tempos e forças em objetivos individuais de caráter imediato.

Como exemplo disso, durante a realização do grupo focal, uma das etapas da pesquisa com os estudantes do curso Técnico em Agropecuária do campus Catu, quando observamos e comentamos sobre as ausências de alunos da turma ao compararmos com o quantitativo inicial que preencheu o questionário da pesquisa em etapas anteriores, ouvimos do grupo participante a avaliação de seus pares de que os colegas evadidos "não tiveram foco" nos estudos ou "não tiveram firmeza" dos seus propósitos enquanto estudantes de Instituto Federal, considerado "exigente" e "qualificado" pelos sujeitos presentes.

A partir da contextualização dessas falas dos sujeitos da pesquisa com as causas da evasão e retenção discente indicadas nos diagnósticos da Rede Federal e citadas anteriormente neste texto observamos que eles compreendem o fenômeno da evasão dos pares, a partir de uma visão meritocrática do cenário, atribuindo exclusivamente às condições individuais do estudante, como por exemplo "não foram fortes", "desistiram", "não tiveram força de vontade"... o que pode sinalizar como os sujeitos percebem seus processos de formação distanciados da concepção de políticas educacionais como direito e do cenário de instabilidade socioeconômica que avançava nas condições familiares e seus contextos de vida. 


\section{REFERÊNCIAS}

ABRAMO, Helena Wendel. Condição juvenil no Brasil contemporâneo. In: ABRAMO, H.; BRANCO, P.P.M. Retratos da juventude brasileira: análises de uma pesquisa nacional. São Paulo: Instituto Cidadania; Fundação Perseu Abramo, 2005. p. 37-73.

ARROYO, Miguel Gonzalez; CALDART, Roseli Salete; MOLINA, Mônica Castagna (Org.). Por uma educação do campo. Petrópolis, RJ: Vozes, 2004.

BRASIL. Conselho Nacional de Educação. Câmara de Educação Básica. Parecer CEB N ${ }^{o}$ 36/2001. Diretrizes Operacionais para Educação Básica nas Escolas do Campo, 2002. Disponível em http://portal.mec.gov.br/cne/arquivos/pdf/EducCampo01.pdf. Acesso em: 30 ago. 2019

BRASIL. Ministério da Educação. Secretaria de Educação Profissional e Tecnológica. Documento Orientador para a Superação da Evasão e Retenção na Rede Federal de Educação Profissional, Científica e Tecnológica. Brasília, DF, 2014. Disponível em http://portal.mec.gov.br/index.php?option=com_docman\&view=download\&alias=110401 -documento-orientador-evasao-retencao-vfinal\&category_slug=abril-2019pdf\&Itemid=30192. Acesso em: 24 jan. 2020

BRASIL. Ministério da Educação. Plataforma Nilo Peçanha. Brasília: MEC/SETEC, 2018-2019. Disponível em: https://www.plataformanilopecanha.org/. Acesso em: 21 jan. 2020.

“CAMINHOS DO TRABALHO”. Direção: CAVALCANTE, Ludmila Oliveira Holanda; ABREU; Luciane Ferreira; SILVA, Fábio Dantas Silva. Financiamento do Conselho Nacional de Desenvolvimento Científico e Tecnológico (CNPq). Apoio Universidade Estadual de Feira de Santana (UEFS). Instituto Federal Baiano (IF Baiano) Campus Catu. Produção: Volney Meneses. Feira de Santana. Bahia. Dezembro de 2018. Disponível em https://www.youtube.com/watch?v=t8ul9TBUmjg\&feature=youtu.be

CASTRO, Elisa Guaraná. Juventude Rural no Brasil: processos de exclusão e a construção de um ator político. Revista LatinoAmericana de Ciencias Sociales, Niñez e Juventud. Vol. 7, No 1, Enero -Junio 2009, Colômbia, 2009a. Disponível em http://revistaumanizales.cinde.org.co/index.php/Revista-Latinoamericana/issue/view/10. Acesso em: 12 jul. 2018

CASTRO, Elisa Guaraná et al. Os jovens estão indo embora?: juventude rural e a construção de um ator político. Rio de Janeiro: Mauad X; Seropédica, RJ : EDUR, 2009

COMISSÃO ORGANIZADORA JOIF - Jogos Internos do IF Baiano Catu. Nota JOIF 2016. Catu, 21/10/16

DAYRELL, Juarez Tarcísio; JESUS, Rodrigo Ednilson de. Juventude, Ensino Médio e os processos de exclusão escolar. Educação e Sociedade, Campinas, v. 37, nº . 135, abr.-jun., 2016. Disponível em http://www.scielo.br/pdf/es/v37n135/1678-4626-es-37-135-00407.pdf.

DAYRELL, Juarez Tarcísio. A escola faz juventudes?: reflexões em torno da socialização juvenil. Educação \& Sociedade, Campinas, v. 28, n. 100, p.1105-1128, out. 2007. 
FERNANDES, Bernardo Mançano. Os campos da pesquisa em educação do campo: espaço e território como categorias essenciais. I Encontro Nacional de Pesquisa em Educação do Campo, Brasília. 2005. Disponível em http://portal.mec.gov.br/secad/arquivos/pdf/educacaodocampo/artigo_bernardo.pdf. Aceso em: 05 abr. 2019

GEELS - Grêmio Estudantil Edson Luís Souto. Ofício No 42/2016. Ocupação estudantil em prol de um país digno. Catu, 19/10/16

GONDIM, Sônia Maria Guedes. Grupos focais como técnica de investigação qualitativa: desafios metodológicos. Paidéia, 2003, 12(24), 149-16. Disponível em: http://www.scielo.br/pdf/paideia/v12n24/04.pdf. Acesso em: 03 out. 2018

IBGE - Instituto Brasileiro de Geografia e Estatística. População estimada: IBGE, Diretoria de Pesquisas, Coordenação de População e Indicadores Sociais. Estimativas da população residente com data de referência 10 de julho de 2018. 2018a. Disponível em: https://cidades.ibge.gov.br/brasil/ba/Catu/panorama. Acesso em: 06 abr. 2019.

\section{Pesquisa Nacional por Amostra de Domicílios Contínua. Educação 2017.}

Diretoria de Pesquisas, Coordenação de Trabalho e Rendimento. 2018b. Disponível em https://biblioteca.ibge.gov.br/visualizacao/livros/liv101576_informativo.pdf. Acesso em: 06 dez. 2019

IF BAIANO - Instituto Federal de Educação, Ciência e Tecnologia Federal Baiano. Plano Estratégico Institucional para a Permanência e Êxito dos Estudantes. Salvador, 2016. Disponível em: https://ifbaiano.edu.br/portal/ensino/wpcontent/uploads/sites/2/2016/06/PLANO_OFICIAL_13_DE_JUNHO.pdf. Acesso em: 05 jan. 2020

IF BAIANO - Instituto Federal de Educação, Ciência e Tecnologia Federal Baiano. Relatório de Gestão 2016. Salvador, 2016. Disponível em:

file:///C:/Users/usuario/Downloads/Relat\%C3\%B3rio-de-Gest\%C3\%A3o-2016.pdf

IF BAIANO - Instituto Federal de Educação, Ciência e Tecnologia Federal Baiano. Relatório de Gestão 2019. Salvador, 2019. Disponível em: file:///C:/Users/usuario/Downloads/RG2019-27.08.2020-TCU.pdf

INEP - Instituto Nacional de Estudos e Pesquisas Educacionais Anísio Teixeira. Resumo Técnico: Censo da Educação Básica 2018 [recurso eletrônico]. - Brasília: Instituto Nacional de Estudos e Pesquisas Educacionais Anísio Teixeira, 2019. Disponível em:

file:///C:/Users/usuario/Downloads/Resumo\%20T\%C3\%A9cnico\%20\%20Censo\%20da\%20Educa\%C3\%A7\%C3\%A3o\%20B\%C3\%A1sica\%202018\%20(1).pdf. Acesso em: 02 abr. 2019.

KUENZER, Acacia Zeneida. Sistema educacional e a formação de trabalhadores: a desqualificação do Ensino Médio Flexível. Ciência \& Saúde Coletiva, 25(1):57-66, 2020.

LEÃO, Geraldo; ANTUNES-ROCHA, Maria Isabel. (Org.). Juventudes do campo. Belo Horizonte: Autêntica, 2015. 
MOTTA, Vânia Cardoso da; FRIGOTTO, Gaudêncio. Por que a urgência da reforma do ensino médio? Medida provisória $n^{\circ} 746 / 2016$ (lei $n^{\circ}$ 13.415/2017) Educ. Soc., Campinas, v. 38, nº 139 , p.355-372, abr.-jun., 2017.

MORAES, Gustavo Henrique et. al. Plataforma Nilo Peçanha: guia de referência metodológica. Brasília: ed. Evobiz, 2018. Disponível em: https://drive.google.com/file/d/1WLWTxdjNej448_VMVGsbC-wLMiT7r-9d/view. Acesso em 12 fev. 2020.

SANTOS, Milton. Da totalidade ao lugar. São Paulo: Editora da USP, 2012.

SOUZA, Maria Antônia de. Educação do campo, desigualdades sociais e educacionais.

Educação \& Sociedade, vol.33, No 120 Campinas Jul/Set. 2012. Disponível em: http://www.scielo.br/scielo.php?script=sci_arttext\&pid=S0101-73302012000300006. Acesso em 30. Nov 2019

\section{SOBRE OS AUTORES:}

\section{Ludmila Oliveira Holanda Cavalcante}

Doutora em Educação pela Universidade Federal da Bahia (UFBA); Professora Titular do Departamento de Educação e professora do Programa de Pós Graduação em Educação da Universidade Estadual de Feira de Santana (UEFS). Membro do grupo de Pesquisa Educação do Campo/UEFS. E-mail: ludmilaholanda@yahoo.com

(iD https://orcid.org/0000-0002-0802-9188

\section{Fabio Dantas de Souza Silva}

Doutor em Educação pela Universidade Federal da Bahia (UFBA); Professor Titular do Departamento de Educação e professor do Programa de Pós Graduação em Educação da Universidade Estadual de Feira de Santana (UEFS). Membro do grupo de Pesquisa Educação do Campo/UEFS. E-mail: fabdant@ hotmail.com

iD https://orcid.org/0000-0003-3227-2388

\section{Luciane Ferreira de Abreu}

Mestre em Educação pela Universidade Estadual de Feira de Santana (UEFS); Pedagoga no Instituto Federal de Educação, Ciência e Tecnologia Baiano - campus Alagoinhas (BA). Membro do grupo de Pesquisa Educação do Campo/UEFS e do Grupo de Pesquisa em Educação, Anticolonialismo, Linguagens e Subjetividades do IF Baiano. E-mail: luciane.abreu@hotmail.com

iD https://orcid.org/0000-0002-9567-6307 